
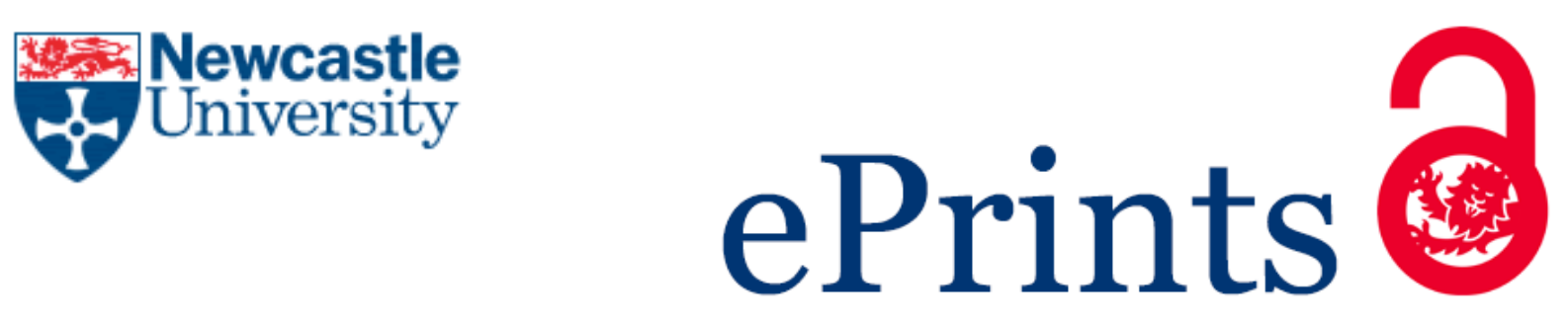

Schartner A.

'You cannot talk with all of the strangers in a pub': a longitudinal case study of international postgraduate students' social ties at a British university. Higher Education 2015, 69(2), 225-241

\title{
Copyright:
}

The final publication is available at Springer via http://dx.doi.org/10.1007/s10734-014-9771-8

Date deposited:

$15 / 07 / 2015$

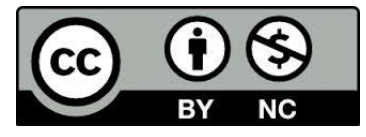

This work is licensed under a Creative Commons Attribution-NonCommercial 3.0 Unported License 


\section{'You cannot talk with all of the strangers in a pub.' A longitudinal case study of international postgraduate students' social ties at a British university}

The final publication is available at Springer via http://dx.doi.org/ 10.1007/s10734-014-9771-8

\section{Background}

An increasing number of students study at higher education (HE) institutions outside their country of origin, predominantly at English-speaking universities (OECD 2012). These academic sojourns ${ }^{1}$ abroad are a growing, global educational and intercultural ${ }^{2}$ phenomenon, and the 'international student experience' (Hellstén and Prescott 2004) has attracted considerable research interest over the years (see Andrade and Evans 2009 for a review). There are currently around 4 million international students worldwide, representing an increase of 99 per cent since the year 2000 (OECD, 2012). Various terms have been used to refer to this student group, including student sojourners, foreign students, and overseas students. All these terms commonly describe individuals who leave their country of origin to undertake tertiary study abroad ${ }^{3}$ (Ramsay, Jones and Barker 2007). Despite considerable competition from its European neighbours, the United Kingdom (UK) remains the main European destination country for international students, and the second most popular globally after the United States (US): in 2010-11, 19 per cent of the UK's total HE student body, and 70 per cent of those undertaking full-time postgraduate taught (PGT) degrees, were non-UK (UKCISA 2013).

A glance at the academic and wider educational literature reveals that references are often made to the transformative potential of an academic sojourn abroad, in terms of aiding personal growth and intercultural competence (Drews, Meyer and Peregrine 1996; Brown 2009a). According to the European Commission (2013), a study sojourn abroad can 'improve language learning, intercultural skills, self-reliance and self-awareness'. However, despite its many benefits for students, study abroad also entails leaving one's comfort zone at home, and

\footnotetext{
${ }^{1}$ A sojourn is commonly understood as a temporary stay abroad for a specific purpose such as academic study (Ward, Bochner and Furnham, 2001).

${ }^{2}$ This article uses inter and cross cultural synonymously throughout, although there is some debate about distinctions between the two (e.g. Gudykunst, 2003).

${ }^{3}$ Who is considered an international student may vary for legal or tuition fee purposes (Gürüz, 2008). For example in the UK students from the European Union are counted as 'international' in the national statistics, but pay the lower 'home' tuition fee.
} 
involves the temporary loss of social ties and familiar social support systems (Hayes and Lin 1994), resulting in a lack of social connectedness for the individual student sojourner (Ward et al. 2001). As Neri and Ville (2008: 1515) note 'international university students arrive in the host country generally denuded of social capital'. Consequently, the formation of new social ties becomes a paramount objective for the student sojourner (Ong and Ward 2005). In comparison to their domestic peers, international students need to make extra efforts to achieve social integration in the new environment as their familiar social networks are usually not within easy reach (Rienties et al 2012).

A considerable body of research has highlighted the importance of social connectedness for student sojourners' subjective wellbeing, and their academic and sociocultural adjustment (see Ward et al. 2001 for a review). However, few systematic attempts have been made to monitor the trajectories of international students' social ties over time using qualitative methods of inquiry (for an exception see Montgomery and McDowell 2009). Most studies to date have employed a cross-sectional quantitative design and have typically counted the number of friends students had in the host country (e.g. Bochner, Hutnik and Furnham 1985; Furnham and Alibhai 1985; Neri and Ville 2008; Hendrickson, Rosen and Aune 2011). Therefore, the present case study set out to delve deeper into the social experience of student sojourners by tracking a specific group of students longitudinally throughout their sojourn in the UK. A qualitative approach was the method of choice as it was felt that this would best capture students' 'lived' experience in their own words, and would therefore complement prior larger scale quantitative research referred to above. More specifically, this study looked to explore not only the trajectories of students' social ties over time, but also the functions and purposes of different social groups as discussed below.

One of the earliest studies of international students' social contact patterns was Bochner, McLeod and Lin's (1977) study of 30 student sojourners in Hawaii. Participants were asked to identify their five 'best friends' and the five people with whom they spend most of their time. Based on their findings, the authors proposed the Functional Model of Friendship Networks (FMFN) which classifies student sojourners' social ties into three separate categories with different levels of salience and distinct functions (Table 1). The model depicts ties with co-nationals as students' primary network, followed by a secondary network of host national ties, and a tertiary network of non-co-national international ties.

Table 1 The Functional Model of Friendship Networks (Bochner et al. 1977) 


\begin{tabular}{lll}
\hline $\begin{array}{l}\text { Primary } \\
\text { Co-National }\end{array}$ & $\begin{array}{l}\text { Contacts with other } \\
\text { sojourning compatriots }\end{array}$ & $\begin{array}{l}\text { Close friendships; } \\
\text { express/rehearse the culture } \\
\text { of origin }\end{array}$ \\
Secondary & $\begin{array}{l}\text { Bonds with significant } \\
\text { host nationals (e.g. } \\
\text { students academics, } \\
\text { officials) }\end{array}$ & $\begin{array}{l}\text { Instrumental; facilitate } \\
\text { academic and professional } \\
\text { aspirations }\end{array}$ \\
Tertiary & $\begin{array}{l}\text { Non-co-nationals, } \\
\text { including fellow } \\
\text { international students }\end{array}$ & $\begin{array}{l}\text { Companionship for } \\
\text { recreational activities }\end{array}$ \\
\hline
\end{tabular}

Furnham and Alibhai (1985) replicated Bochner et al.'s (1977) study with a larger and more diverse sample of 140 student sojourners in the UK. Although conducted on a larger scale and in a different host country, the results from Furnham and Alibhai's study corresponded largely to those of Bochner and colleagues. However, more recent research by Hendrickson et al. (2011) found that student sojourners at a Hawaiian university reported higher ratios of host nationals in their social network than co-nationals. The authors posit that this might be due to the study design which asked students to provide an exhaustive list of their friends as opposed to earlier studies which limited the list to a specific number of best friends (see Bochner et al. 1977; Furnham and Alibhai 1985), thus making it more likely that students would include more casual ties with host nationals.

Overall, three key trends with regard to social contact patterns can be discerned in the wider international student literature. First, and in line with the FMFN, a number of studies have identified ties with co-nationals as the primary social network of student sojourners (e.g. Furnham and Alibhai 1985; Maundeni 2001; Neri and Ville 2008). Co-national ties have been found to fulfil an important support function among individuals going through the sojourn experience by buffering acculturative stress (Kim 2001; Woolf 2007). However, co-national contact has also been found to have adverse effects on language development and adjustment to the host environment (Maundeni 2001). Secondly, research has shown that while international students generally desire and expect to form relationships with members of the host community (Sakurai, McCall-Wolf and Kashima 2010), student sojourners across a number of locations, including the UK, consistently report a lack of meaningful contact with host nationals (Merrick 2004; Brown, 2009b). For example in a large-scale survey by UKCOSA (2004), 70 per cent of surveyed PGT students in the UK stated that they had no British friends at all. Despite this paucity of host ties, researchers have repeatedly pointed to the benefits of host national contact, including its ability to evoke 'host communicative competence' (Kim 2001) in the student sojourner. Finally, the role of contact between student sojourners of different nationalities, what Sovic (2009) terms 'cosmopolitan friendships', has 
recently attracted growing research attention although this type of contact remains largely under-explored (Young et al. 2013). Nonetheless, recent research points to the increasing importance of these 'international ties' (e.g. Kashima and Loh 2006; Montgomery and McDowell 2009). For example, in a study of social contact patterns among a sample of 100 international students in Australia, Kashima and Loh (2006) found that the more international ties students had, the better adjusted they were psychologically and the more they identified with their Australian host university. Similarly, Montgomery and McDowell's (2009) longitudinal UK-based study found evidence for a closely-knit and highly supportive 'international community of practice', a trend also observed in Young et al.'s (2013) study of PGT students in the UK.

Although Bochner et al.'s (1977) FMFN is somewhat outdated it is still frequently cited in the student sojourner literature (Ward et al. 2001; Hendrickson et al. 2011). However, to the best of the author's knowledge, no study has investigated the FMFN from a qualitative perspective, or its applicability over time, nor has its relevance to the UK HE context been tested in recent research. In light of the recent surge in international student numbers, it is likely that the conditions for the formation of social ties may have changed substantially since Bochner and colleagues undertook their study. Therefore, the conceptual aim of the present study was to develop a more current model of student sojourners' social contact patterns. While Bochner et al. (1977) focused mainly on the quantity of social contacts and its functions at one point in time, the model put forward in this case study is informed by indepth qualitative data. The case study approach allowed for rich data to be collected from one particular institutional context, while also allowing for qualitative comparisons to other similar contexts (Denscombe 2003). At the same time, the focus on students' social realities within one particular institutional setting has useful practical applications for the research site (Turner and Robson 2007), most especially for its internationalisation agenda.

The research question for this study was:

- What are the dynamics and functions of student sojourners' social ties over time? Moreover, the specific research interest was in the three friendship networks suggested in the FMFN: (1) social ties with co-nationals, (2) social ties with host nationals (i.e. British people), and (3) social ties with other non-co-national student sojourners (i.e. 'international ties').

\section{Methods}

Setting and participants 
The setting for this study was a university in the North East of England (student population 20,660). In order to monitor social contact patterns over time, a qualitative, longitudinal approach was the method of choice. It was hoped that this would allow for students' 'lived' experience to be captured without over-relying on retrospective accounts. Three waves of semi-structured interviews were conducted with a sample of student volunteers $(\mathrm{N}=20)$ over the course of their academic sojourn in the UK (Figure 1).

Figure 1 The Interview Process for this Study

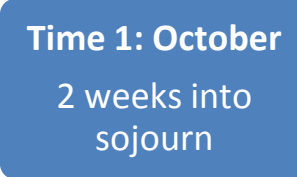

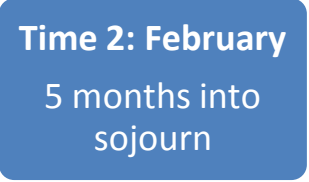

Time 3: June

9 months into

sojourn

All interviewees were undertaking one-year taught postgraduate MA degrees at the same host university in the North East of England. In order to maximise homogeneity, students were recruited from two MA degrees in the same faculty which were similar in terms of structure (with a taught component running from October to June and a student-guided research project from June to August) and student cohort composition (with around 90\% of students being non-UK). Keeping participation limited to these two programmes maximised the homogeneity of the group in terms of academic demands and opportunities for social interaction (cf. Wright and Author 2013). Students were informed about the research project in a lecture in the first week of teaching. The only selection criteria were that particpants should not hold any academic qualifications from UK universities, and that they should vary in nationality. Motivation to participate in the project was high and 60 students volunteered in total. The volunteers were contacted via e-mail to confirm their initial expression of interest. Of those who replied, the first 20 were selected as participants. Although purposive sampling is common in qualitative research (Williams 2003), it was hoped that this approach would represent a more random sampling procedure. Overall, it resulted in a fairly representative sample of the overall cohorts: 14 females and 6 males from 13 different countries (22-28 years of age, Table 2).

Table 2 Interviewee Profiles

\begin{tabular}{llclccl}
\hline Pseudonym & Age & $\begin{array}{c}\text { Country of } \\
\text { Origin }\end{array}$ & Sex & $\begin{array}{c}\text { Experience } \\
\text { Abroad }\end{array}$ & Accommodation \\
\hline 1 & Anna & 22 & Romania & F & N & University \\
2 & Celik & 23 & Turkey & M & N & University \\
3 & Esma & 22 & Turkey & F & Y & Private \\
4 & Elya & 23 & Malaysia & F & N & University \\
5 & Ella & 23 & Italy & F & Y & Private \\
& & & & & &
\end{tabular}




\begin{tabular}{llllccl}
6 & Flora & 26 & Germany & F & Y & Private \\
7 & Gediz & 24 & Turkey & M & N & University \\
8 & Gabriel & 23 & Lithuania & M & N & University \\
9 & Indah & 26 & Indonesia & F & Y & University \\
10 & Kaari & 27 & Finland & F & N & Private \\
11 & Lydia & 24 & Romania & F & N & University \\
12 & Mario & 25 & Mexico & M & Y & University \\
13 & Mita & 28 & Indonesia & F & N & Private \\
14 & Robin & 23 & USA & M & Y & University \\
15 & Sarah & 26 & USA & F & N & University \\
16 & Silvia & 24 & Slovakia & F & Y & Private \\
17 & Ting & 23 & China & F & N & Private \\
18 & Tao & 23 & China & M & N & University \\
19 & Victoria & 23 & Latvia & F & Y & University \\
20 & Ying & 24 & China & F & N & University \\
\hline
\end{tabular}

All interviews were conducted individually, in English, in a quiet location on campus ${ }^{4}$ and varied in length between 20 minutes and one hour. The researcher's role as postgraduate teaching assistant allowed for close involvement with PGT students and thus maximised possibilities for data-collection (cf. Brown 2008). Furthermore, the continuity induced by this role allowed for rapport to be built with the interviewees, a factor that is crucial for the success of a longitudinal research project (Spradley 1979). Nonetheless, it must be acknowledged that the dual-role of researcher and instructor might lead to ethical challenges such as a possible conflict of interest (MRU 2012). In the case presented here, some interviewees also attended seminars led by the researcher; however these did not include an assessed component. Wherever the researcher was involved in assessment, this was anonymous thus mitigating a potential conflict of interest. Nonetheless, it might still be possible that students were inhibited by power dynamics associated with the role as instructor (Ball 1983) although students' talk in the interviews seemed natural and free-flowing.

While an interview guide was used as 'scaffolding' for all interviews, flexibility and spontaneity were preserved by using probing questions emerging from the students' accounts (Mason 2002). All interviews were audio recorded, transcribed for analysis and then anonymised. Pseudonyms are used throughout this paper instead of the students' real names.

\section{Data analysis}

\footnotetext{
${ }^{4}$ Two interviewees were first language English speakers from the US and thus used their native language in the interviews. However, all other participants had previously fulfilled the host university's English language entrance requirement of IELTS 6.5 or equivalent and were thus considered well-equipped to take part in an interview of this kind.
} 
Data-collection resulted in 58 transcripts ${ }^{5}$ which were analysed using thematic analysis (Boyatzis 1998). As the process for theme generation is rarely made explicit in qualitative research studies (Ryan and Bernard 2003), this study used a novel approach to maximise clarity and trustworthiness (cf. Young and Author, 2014). Using NVivo 9, students' comments were initially sorted according to the three social groups proposed in the FMFM. Next, responses were sorted into four broad analytical categories: positive, negative, neutral, and problematizing comments (Table 3).

Table 3 Example Comments for Analytical Categories

\begin{tabular}{|c|c|}
\hline Analytical Category & Example Comments \\
\hline $\begin{array}{l}\text { Positive } \\
\text { Positive } \\
\text { orientation/experience }\end{array}$ & $\begin{array}{l}\text { I like it [the programme] because it's very international. } \\
\text { (Anna, T2) }\end{array}$ \\
\hline $\begin{array}{l}\text { Negative } \\
\text { Negative } \\
\text { orientation/experience }\end{array}$ & There are too many Chinese students. (Celik, T2) \\
\hline $\begin{array}{l}\text { Problematizing } \\
\text { Discussing the } \\
\text { problematic/complex } \\
\text { nature of an issue }\end{array}$ & $\begin{array}{l}\text { It is a little bit more challenging to work in a group with } \\
\text { more Chinese students. (Veronika, T2) }\end{array}$ \\
\hline $\begin{array}{l}\text { Neutral } \\
\text { An impartial } \\
\text { statement }\end{array}$ & $\begin{array}{l}\text { I'm kind of surprised because there aren't that many British } \\
\text { students taking the master's degree. (Lydia, T1) }\end{array}$ \\
\hline
\end{tabular}

In a third analytical step, every statement in the four broad categories was further analysed for content and placed under an appropriate heading or thematic 'node', along with any others which were sufficiently similar (Hannan 2007). This inductive process generated a collection of emerging (sub)themes. Findings are presented below, supported by verbatim quotations from the students in order to establish a clear link with the raw data.

\footnotetext{
${ }^{5}$ One interviewee only took part in the second interview wave (February)
} 


\section{Findings}

Overall, Bochner et al.'s (1977) typology of three categories of social ties was supported, albeit slightly more nuanced, with all three social groups present in participants' social lives. However, the functions of these three networks were found to be somewhat in contrast to the FMFN, and distinct trajectories emerged over time as discussed below.

\section{Ties with host nationals}

Students arrived in the UK with a strong desire for host national contact and had generally high aspirations to mix with British ${ }^{6}$ people, and to learn about 'British culture':

I would like to know more things about British culture, like eat at someone's house with her British mum and something like that. (Mario, T2)

Host ties were also viewed as a key source of country-specific information:

[...] it's important to at least know somebody [...] who can recommend some places, or who can tell you where to buy cheap sheets and curtains. (Kaari, T1)

Some students also acknowledged that host national contact might offer opportunities for language development:

It surely can improve my spoken language. (Ying, Chinese, 24, T1)

Despite strong motivation to interact with host nationals, students' expectations and aspirations to form ties with British people were largely disappointed, and comments such as 'I want to meet more British people.' (Anna, T2) and 'I was hoping to meet more British people.' (Flora, T2) were common across the sample. Instigating and maintaining contact with British people was repeatedly described as 'difficult' and an apparent lack of host contact persisted throughout the sojourn for most interviewees as is illustrated in Anna's and Victoria's case below:

\begin{tabular}{|c|c|c|c|}
\hline & T1 - October & T2 - February & T3 - June \\
\hline Anna & $\begin{array}{l}\text { I haven't met too } \\
\text { many British people } \\
\text { so far. }\end{array}$ & $\begin{array}{l}\text { I think it is very } \\
\text { difficult to make } \\
\text { British friends. }\end{array}$ & $\begin{array}{l}\text { I don't have any } \\
\text { British friends. }\end{array}$ \\
\hline Victoria & $\begin{array}{l}\text { I have met, like talked } \\
\text { to a few British } \\
\text { people but we are not, } \\
\text { like friends in the full } \\
\text { term [...] }\end{array}$ & $\begin{array}{l}\text { I don't have a lot of } \\
\text { British friends here, } \\
\text { like if you think about } \\
\text { it not even one. }\end{array}$ & $\begin{array}{l}\text { I don't even think that } \\
\text { I have like a friend, } \\
\text { like a British friend at } \\
\text { all here which is quite } \\
\text { strange because I am } \\
\text { in UK. }\end{array}$ \\
\hline
\end{tabular}

\footnotetext{
${ }^{6}$ The terms British and English were used interchangeably by the students
} 
Underlying this persistent lack of host contact were a number of structural issues, including an apparent lack of places to meet British people:

$[\ldots]$ you cannot talk with all of the strangers in a pub. (Esma, T2)

$[\ldots]$ they are not here. I don't know where they are. (Mario, T2)

Students also highlighted skewed student intake and residence in 'international' university accommodation. The latter resulted in feelings of isolation and segregation from the local community:

I am living in university accommodation, so I don't have any neighbours, any local people. (Celik, T1)

The highly internationalised study setting was reflected in the social activities available to students and was perceived by some as a barrier to meeting local students:

[...] there's international socials, international something, meeting, so it's always international. (Gabriel, T2)

Overall, contact with British people was described as superficial and remained largely restricted to brief service encounters which made conversation beyond standardised, formulaic interaction difficult:

It's just the lady I meet in Tesco or the cab driver [...] (Elya, T2)

$[\ldots]$ in shops they have like three phrases. It's "Hello, do you need your bagging, do you have your club card?" and it's always the same. (Gabriel, T2)

Contact with local students was particularly difficult to instigate, and several interviewees pointed to segregations between British and international students, and observed an apparent lack of interest and initiative on the part of the former:

[...] I think they already have their own group of friends probably. (Mita, $\mathrm{T} 2)$

British prefer to be friends with British. I guess that's maybe because of the language or maybe for some other reasons, I don't know. (Victoria, T2)

A perceived lack of common conversational topics and high international student numbers on the host campus were also identified as contributing to this segregation:

[...] maybe we can only talk about basic things, about the modules $[\ldots]$ the talkings are not interesting for them maybe. (Gediz, T2)

I guess British people are a bit maybe fed up of the internationals $[\ldots]$

(Silvia, T2)

However, to an extent students were able to compensate for the dearth of host contact by forming ties with fellow international students. It seems that a lack of contact with the British 
host community resulted in greater attachment to the community of international students, and seemed able to lead a fulfilling social life largely independent of the host community. This is reflected in the following comments:

I feel like I practice my English every day just speaking with other international students [...] I don't really feel like I need the British and have a conversation. (Lydia, T1)

I think I don't really lack the British [...] I quite enjoy the different range of nationalities and cultures. (Silvia, T2)

\section{Ties with co-nationals}

Social contact with compatriots seemed to polarise the students with some interviewees explicitly stating that they wanted to avoid all co-national contact while in the UK:

I can meet Italians in Italy, why should I meet new Italians here? (Ella, T1)

I know millions of Turkish people in Turkey. (Esma, T1)

Others retreated to the safety of compatriot circles, most especially in the early sojourn stages when instances of homesickness and loneliness were most salient. It seems that co-national contact fulfilled an important psychological role when students were most unfamiliar with the new environment. Several interviewees pointed to the 'comforting' nature of co-national interaction, commenting on the importance of a 'shared culture' and a 'common language':

You consider people from your country more like family [...] (Anna, T1)

You share the common culture, so you feel more relaxed. (Celik, T1)

[...] we can eat the same things and if we miss home sometimes we just share stories about what we like doing back home and I can speak my language. (Mita, T1)

However, students also seemed to find themselves torn between, on the one hand, wanting conational friends, and on the other hand, feeling they ought to seize every opportunity for intercultural interaction. This dilemma is best encapsulated in the quotes below:

I would like to have Turkish friends but I don't want to spend too much time with them. (Celik, T1)

It's very complicated emotion. Of course I feel happy when I meet Chinese friends $[\ldots]$ but at the same time I also expect to make friends with British or other countries people [...] when you choose Chinese you also will feel a little regret to choose them. (Ting, T1)

Some students felt that extensive co-national interaction could be detrimental to their English language development:

It's not that I don't want to hang out with them [...] I just want to improve my English skill. (Indah, T2) 
The complexity of co-national ties is illustrated in Figure 2 below.

Figure 2 The Complexity of Co-National Ties

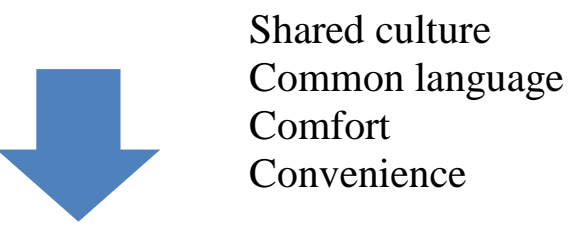

\section{Language development Personal growth 'Culture-learning'}

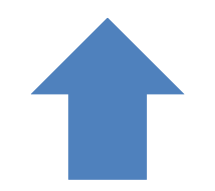

As the sojourn progressed, students who initially retreated to the safety of compatriot circles became more eager and more prepared to engage with those outside of their co-national community. A number of interviewees reported an increasing desire and growing confidence to interact with non-co-nationals:

I think I've definitely been challenging myself to spend more time with people who are completely different than me [...] (Sarah, T2)

One aspect of co-national contact that was perhaps most dominant was 'virtual' contact with friends and family back home. Most interviewees contacted home at least on a weekly basis, and some several times a day:

[...] I go on Facebook and it's like two hours every day talking to my friends in Mexico and I talk to my mum like once a week through Skype. (Mario, $\mathrm{T} 2)$

You know Skype is not so expensive, so I can communicate with them every day. (Tao, T2)

This form of co-national contact seemed to play an important role for students' own sense of wellbeing:

[...] it helps a lot to keep them up to date with my experience here, to get the news from them and it's vital for my wellbeing actually. (Lydia, T2)

\section{International ties}

Students were generally enthusiastic about intercultural interaction and statements such as 'I just want to meet people from all over the world' (Mita, T1) were common right across the 
sample. Ties with other non-co-national sojourners emerged quickly, and overwhelmingly, as the students' primary network as illustrated below:

The most time I spend with international students and then probably the second is with people from my own country but that is actually just my boyfriend [...] the less time is with the native English people. (Lydia, T2)

The interviewees spoke extensively of the benefits of having 'international friends'. Learning from, and about, others was described as an inherent aspect of non-co-national interaction:

We are different and there are lots of things to speak about. (Gabriel, T1)

It's just so nice to get to know new things and to have different views on things. (Flora, T1)

Moreover, international ties fulfilled an important support function based on shared 'foreignness' and a sense of commonality that helped to alleviate the more distressing aspects of a sojourn abroad:

They are also foreigner so I guess when we meet most of them are also homesick. (Mita, T1)

Support, emotional as well as academic, from non-co-national friends remained constant throughout the year for most students:

$[\ldots]$ we've just been really great help, great support to one another. (Elya, T3)

[...] sometimes we have difficulties in the language and everything so we kind of support each other, like "You can do it!" if one of us loses confidence and starts feeling "Oh no, I don't think I can do, I don't know, something." [Mita, T2]

Through discussion of their academic work and proofreading of each other's papers, international ties became an inherent part of the students' learning experience:

[...] I was learning together with two of my friends from the course and we were spending the whole day at the library, that was a different kind of experience and I enjoyed it as well. (Lydia, T2)

Nonetheless, some comments, particularly in the early sojourn stage, related to the challenges associated with forming international ties. Communication across cultures, and in a second language for most, was viewed by some as a barrier to interaction:

I feel quite not very safe to meet with foreign friends because quite different background $[\ldots]$ the communication is not like between Chinese $[. .$.$] (Ting,$ $\mathrm{T} 1)$

When I am talking to foreigners I can't say "Do you want to meet?" [...]

(Celik, T1) 
The size of the Chinese international student community in particular, created unease among some interviewees:

There are too many Chinese people. I feel like I am in China. I don't have any negative attitudes about Chinese people but there are too many here. (Celik, T1)

Chinese students were perceived as 'shy' and several interviewees felt that meaningful conversations were difficult to instigate and sustain, due to an apparent formation of exclusively Mandarin-speaking social groups:

[...] it's a bit difficult here because there are a lot of Chinese people and Chinese people tend to be all together and speak Chinese. (Ella, T1)

It is really hard to make friends with the Chinese because they are just in their group. They speak only Chinese, their English is really bad, you can't communicate with them. (Kaari, T1)

However, overall students gave an overwhelmingly positive account of their interactions with non-co-national peers, and the mixed-nationality setting seemed to promote intercultural understanding and increased open-mindedness, challenging fixed ways of thinking. Towards the end of their sojourn, students were better able to deconstruct stereotypes - intercultural interaction allowed for existing knowledge to be called into question as first-hand contact between students from different countries enabled students to discover unexpected similarities:

I met an incredibly nice guy from Iran and, I don't know, Iran, I always like connected it with war and I never thought about that there is like young people like me [...] it's just so nice when you get to know people and you think "Wow I never thought that I would meet a person from that country who's so similar to me!" (Flora, T3)

To sum up, the overall impression formed by the data is that students compensated the loss of familiar social support systems and the lack of contact with British people with international ties- the social resources previously available to them in their home countries were replaced by a network of fellow student sojourners who, based on shared 'foreignness' and common experiences provided mutual emotional and academic support, resulting over time in closelyknit intercultural friendships which was the primary form of social contact for most students. 


\section{Discussion and conclusion}

This case study strongly indicates that (a) international PGT students in the UK experience a lack of meaningful host contact, (b) there are a range of complexities associated with conational contact, and (c) that international ties play a crucial role for students' wellbeing and sense of belonging. While a lack of host contact has been widely reported in other UK-based research, including in studies of PGT students (e.g. UKCOSA 2004; Young et al. 2013), the latter two findings remain, thus far, relatively under-discussed and therefore make an important contribution to our empirical and conceptual understanding of student sojourners' social ties. A number of important discussion points arise from this study which may have implications for institutional and educational practice in UK HE.

Host national contact was characterised in this study largely by functional and utilitarian interaction as is indeed also suggested by Bochner et al. (1977). However, in contrast to the FMFN, where host national contact occupies a secondary position after conational contact, host ties emerged as a tertiary network on the outermost fringes of students' social lives in this study (Figure 4). Although ties with host nationals were initially desired by the students and valued for their capacity to evoke cultural and linguistic learning (cf. Furnham and Bochner 1986), instigating and maintaining meaningful contact with British people was perceived as difficult which resulted in discontentment and frustration on the part of the international students, at least in the early sojourn stages. After a slight increase in host interaction, as a result of initial encounters with academics and local residents, contact with British people remained consistently low throughout the sojourn, largely restricted to interactions with university staff, and habitual and formulaic conversations with service personnel (Figure 3). This mirrors previous findings from the UK HE context (e.g. UKCOSA 2004; Wright and Author 2013), and provides further corroborative evidence that student sojourners often encounter less host contact than they initially expect (Ward et al. 2001), and that motivation alone does not automatically guarantee host interaction (Brown 2009b).

One question raised by these findings is whether HE institutions can, and should, encourage the integration of international students with host nationals. Although some interpret the widely reported lack of host interaction as a 'ghettoization' of international students (Deardorff 2009), constituting 'a lasting source of disillusionment and disenchantment' (Brown 2009: 440) for this group, findings from this study strongly suggest that this experience may not necessarily be entirely negative from the students' perspective. In fact, the data indicates that students successfully formed a closely-knit 'international 
community of practice' (cf. Montgomery and McDowell 2009), enabling them to have a positive social experience independent of the British host society. The findings provide strong indications of the importance, to students' own sense of wellbeing and belonging, of contact with peers also going through the sojourn experience. After some initial apprehension about cross-cultural communication challenges, international ties increased steadily and quickly emerged as students' primary network (Figures 3-4), going well beyond the recreational function suggested in the FMFN. It may be that the highly 'internationalised' course environment of this sample, one largely devoid of British students, encouraged the formation of international friendships. This raises the question whether international ties are formed by default, as a consequence of the high international student intake on UK PGT degrees, rather than as a result of students' conscious choice. It seems though, as evidence from this and other studies suggests, that international students generally have a great desire for crosscultural interaction (e.g. Brown 2008), and that international friendships play a crucial and highly positive role in the international student experience.

Thus, it seems reasonable for HE institutions and the broader scholarly discourse to advocate ties among student sojourners as a viable, and in fact logical, alternative to host national ties which are traditionally viewed as the single most important factor for achieving a sense of belonging in the host environment (Kashima and Loh 2006). While there are indications in this and other studies that international students want to feel included in the host environment (e.g. UKCOSA 2004), the findings call into question whether this necessarily, and exclusively, means 'fitting in' with host nationals. It seems that student sojourners find their most effective support among their international peers (cf. Montgomery 2010; Young et al. 2013; Young and Author 2014). This also raises the question whose need it is to achieve integration with host nationals. Perhaps it is HE institutions' endeavour to achieve 'internationalisation at home' (Newcastle University 2012) that perpetuates the debate surrounding the need to achieve this form of integration. This paper calls for a more holistic and inclusive understanding of integration, taking into account the importance of links among international students while they study abroad.

This also has implications for our conceptual understanding of the notion 'host community'. Traditionally, this term has been used to refer to either local residents, or more broadly, nationals of the host country. However, this conceptualisation fails to capture the multi-national and multicultural social reality that many international students encounter as part of their sojourn, including increased exposure to fellow student sojourners and international academics. Reflecting this reality, it might be more useful to speak of an 
international 'community of practice', where 'people come together around some common endeavour' (Eckert and McConnell-Ginet 1998: 490).

Moreover, it seems doubtful whether host institutions will be able to tackle the structural forces underlying the reported segregation of international students from the local community (e.g. residence in university accommodation, high international student numbers). For example, although living arrangements undoubtedly provide many opportunities for friendship formation (Wilcox et al. 2005; Young et al. 2013), suggested efforts to house international students with home students (e.g. Sovic 2009; Hendrickson et al. 2010) might prove futile and impractical on campuses with high international student numbers. Moreover, efforts to encourage interaction between home and international students in the classroom (e.g. Kudo and Simkin 2003) might not come to fruition on degree programmes with low numbers of local students such as PGT programmes in the UK.

International ties can be fostered by host institutions both by encouraging interaction among international students outside the classroom - through organised social activities for example - and by incorporating multicultural group activities into the curriculum (Young et al. 2013). In light of efforts to achieve 'internationalisation at home', emphasising the importance of multicultural teamwork as a transferable skill for all graduates ('home' and 'international') might also make local students more inclined to interact with their international peers (Young and Author 2014). Further exploration of the host perspective, including attitudes of domestic students and the wider local community toward international education and growing international student numbers (Brown, 2009b) will be useful if targeted initiatives such as 'buddy-schemes' (Neri and Ville, 2008) and multicultural intervention programmes (Sakurai et al., 2010) are to be effective.

The role of co-national contact in student sojourners' social lives is a further important discussion point. While much of the prior international student literature highlights the centrality of co-national contact (Bochner et al. 1977; Furnham and Alibhai 1985; Neri and Ville 2008), findings from this study do not replicate this trend. Although some gravitation towards compatriot circles occurred in the early sojourn stages when instances of homesickness and loneliness were most salient, over time co-national contact emerged as a secondary network. Co-national contact peaked at around 2-3 three months into the sojourn, before showing a significant drop and levelling off over time (Figure 3). Perhaps the most striking finding relates to the complexities that seem to be associated with co-national contact. It appears that students felt they 'ought to' avoid contact with co-nationals. This resulted in a 
dilemma of, on the one hand, wanting to spend some time with compatriots but at the same time fearing its implicit disadvantages for English language development and personal growth. To the best of the author's knowledge, this study is the first to report in any depth on the complexities associated with co-national contact. This has important implications for the discourse surrounding the international student experience, and raises the question whether host institutions, and indeed the wider HE literature, should put less emphasis on the integration of international students with host nationals, but instead encourage co-national friendships (cf. McKinlay et al. 1996). As Bochner et al. state in their 1977 study, 'co-national bonds are of vital importance to foreign students, and should therefore not be administratively interfered with, regulated against, obstructed, or sneered at' (p. 292). It is important that host institutions recognise the value of co-national bonds for international students' wellbeing and sense of belonging. Findings from this and other UK-based studies have shown that conational contact plays a crucial role in terms of mitigating homesickness and loneliness, most especially in the early sojourn stages (e.g. Brown 2008). What is more, communication technology has evolved immensely in the last decade, creating increased opportunities for 'virtual' co-national interaction (Coleman and Chafer 2011; Hendrickson et al. 2011), thus making host ties an inherent part of student sojourners' social experience during the sojourn, albeit not necessarily face-to-face.

In sum, and despite some individual variation, three distinct trajectories with regard to the three social groups suggested in the FMFN could be teased apart in the data (Figure 3). The concentric circle model (Figure 4) illustrates a snapshot of students' social ties nine months into the sojourn. An alternative typology of student sojourners' social ties is proposed in Table 5, with international ties as the primary network, co-national ties as a secondary network, and host national ties as a tertiary network.

Finally, this study opens up a number of interesting possible directions for future research. Firstly, as this was a case study of one institutional setting, the research could very usefully be replicated in other similar university settings to allow for qualitative comparisons. Secondly, the data was collected from students on a UK PGT programme, where international student numbers currently stand at 70\% (UKCISA 2013). It might be worthwhile to explore the transferability of the findings to the situation of international undergraduate or doctoral students. It might also be interesting to investigate in how far the findings are transferable to institutional settings in other host countries. Future research could very usefully pursue comparative case studies of international students in different host institutions and host countries, perhaps also taking into account the internationalisation agenda of the host 
institution. Finally, it is possible that the interviewee sample was affected by a self-selection bias - all interviewees were volunteers who are likely to be confident, open-minded and linguistically skilled (Young et al. 2013). Thus, their social ties may have followed a trajectory different from that of the general cohort.

Figure 3 Trajectories of Student Sojourners' Social Ties over Time

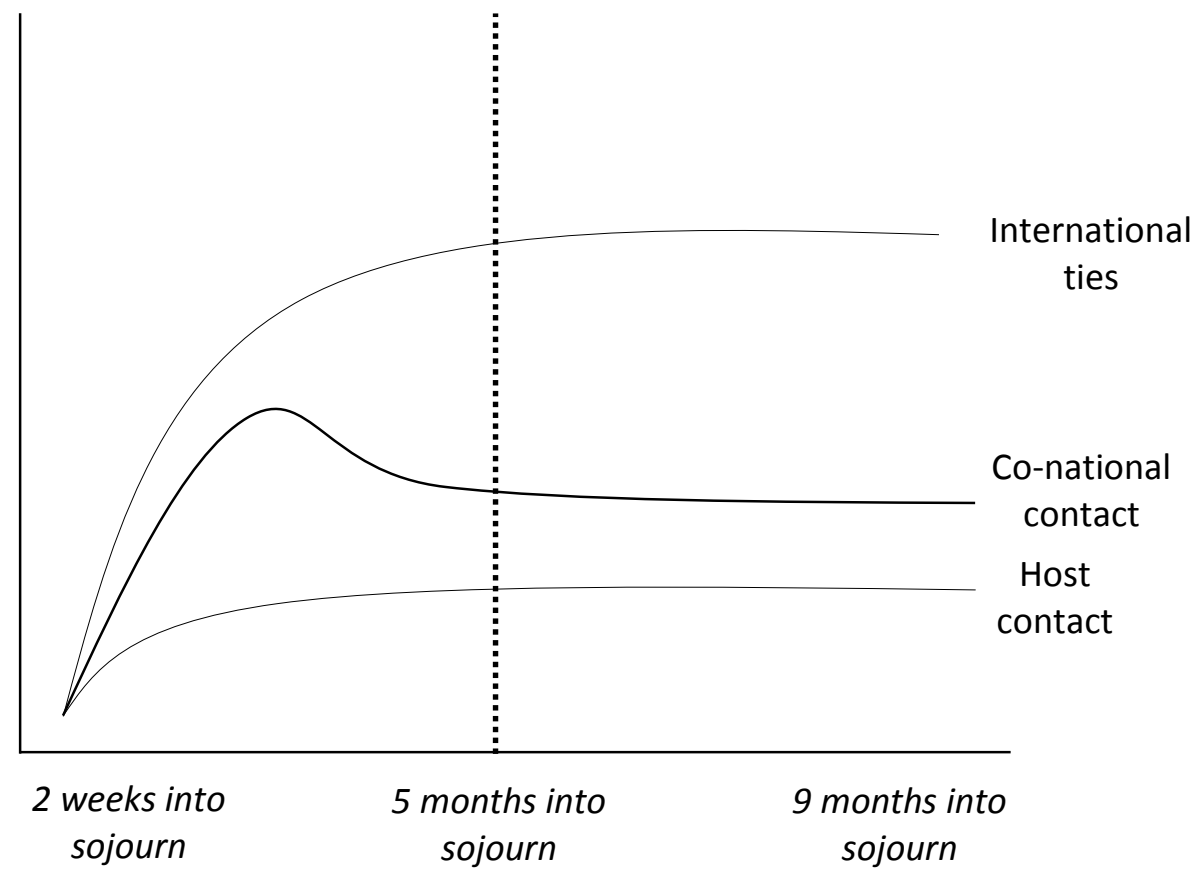

Figure 4 Social Ties of the Students in this Study - 9 Months into Sojourn

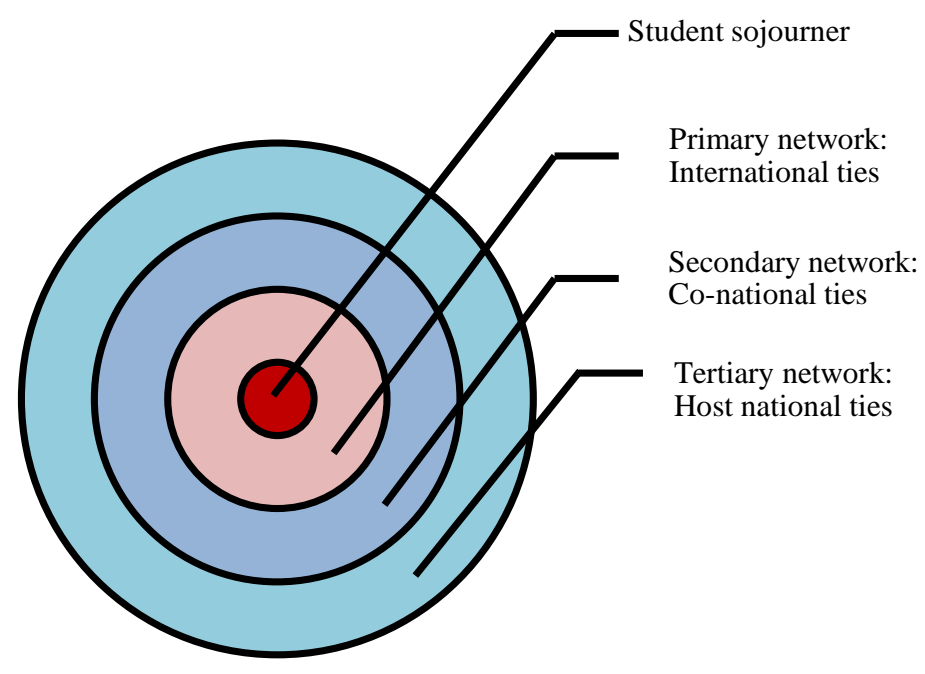

Table 5 Typology and Functions of Social Networks for this Study 


\begin{tabular}{|c|c|c|}
\hline Network & Members & Characteristics \\
\hline $\begin{array}{l}\text { Primary } \\
\text { International }\end{array}$ & $\begin{array}{l}\text { Non-co-nationals, } \\
\text { including fellow } \\
\text { international students }\end{array}$ & $\begin{array}{l}\text { Close friendships; } \\
\text { providing academic and } \\
\text { emotional support }\end{array}$ \\
\hline $\begin{array}{l}\text { Secondary } \\
\text { Co-national }\end{array}$ & $\begin{array}{l}\text { Contacts with other } \\
\text { sojourning compatriots }\end{array}$ & $\begin{array}{l}\text { Emotional support-function } \\
\text { in the early sojourn stage; } \\
\text { complex }\end{array}$ \\
\hline $\begin{array}{l}\text { Tertiary } \\
\text { Host national }\end{array}$ & $\begin{array}{l}\text { Ties with host nationals, } \\
\text { incl. local students }\end{array}$ & $\begin{array}{l}\text { Short-lived; formulaic; } \\
\text { habitual }\end{array}$ \\
\hline
\end{tabular}




\section{References}

Andrade, M.S., \& Evans, N.W. (2009). International students: Strengthening a critical resource. Lanham, MD: Rowman \& Littlefield Education.

Ball, S. (1983). Case study research in education. In M. Hammersley, M. (Ed.), Educational research: Current issues. London: Open University.

Bochner, S., Hutnik, N., \& Furnham, A. (1985). The friendship patterns of overseas and host students in an Oxford student residence. Journal of Social Psychology, 125, 689-94.

Bochner, S., McLeod, B.M,. \& Lin, A. (1977). Friendship patterns of overseas students: A functional model. International Journal of Psychology, 12(4), 277-94.

Boyatzis, R. (1998). Transforming qualitative information: Thematic analysis and code development. Thousand Oaks, CA: Sage Publications.

Brown, L. (2008). The adjustment journey of international postgraduate students at a university in England (Unpublished doctoral thesis), Bournemouth University, UK.

Brown L. (2009a). The transformative power of the international sojourn: An ethnographic study of the international student experience. Annals of Tourism Research 36(3), 502-21.

Brown, L. (2009b). A failure of communication on the cross-cultural campus. Journal of Studies in International Education, 13(4), 439-54.

Brown, L., \& Richards, S. (2012). The British host: just how welcoming are we? Journal of Further and Higher Education, 36(1), 57-79.

Coleman, J.A., Chafer, T. (2010). Study abroad and the Internet: physical and virtual context in an era of expanding telecommunications. Frontiers: The Interdisciplinary Journal of Study Abroad, XIX, 151-67.

Deardorff, D.K. (2009). Connecting international and domestic students. In M Andrade and N. Evans (Eds.), International students: Strengthening a critical resource. Lanham, MD: Rowman \& Littlefield.

Denscombe, M. (2003). The good research guide: For small-scale social research projects ( $2^{\text {nd }}$ Ed.). Maidenhead: OUP.

Drews, D. R., Meyer, L. L., \& Peregrine, P. N. (1996). Effects of study abroad on conceptualizations of national groups. College Student Journal, 30(4), 452-61. 
European Commission (2013a). The Erasmus Programme - studying in Europe and more. Retrieved from http://ec.europa.eu/education/lifelong-learning-programme/erasmus_en.htm

Furnham, A., \& Alibhai, N. (1985). The friendship networks of foreign students: A replication and extension of the functional model. International Journal of Psychology, 20(3-4), 709-22. Furnham, A., \& Bochner, S. (1986). Culture shock: Psychological reactions to unfamiliar environments. London: Methuen.

Gudykunst, W. B. 2003. Cross-cultural and intercultural communication. Thousand Oaks, CA: Sage.

Gürüz, K. (2008). Higher education and international student mobility in the global knowledge economy. Albany, NY: State University of New York Press.

Hannan, A. (2007). Interview in education research. http://www.edu.plymouth.ac.uk/resined/interviews Accessed 10 August 2012.

Hayes, R.L., \& Lin, H.R. (1994). Coming to America: Developing social support systems for international students. Journal of Multicultural Counseling and Development, 22, 7-16.

Hellstén, M., \& Prescott, A. (2004). Learning at university: The international student experience. International Education Journal, 5(3), 344-51.

Hendrickson, B., Rosen, D., \& Aune, K. (2010). An analysis of friendship networks, social connectedness, homesickness, and satisfaction levels of international students. International Journal of Intercultural Relations, 35(3), 281-95.

Kashima, E.S., \& Loh, E. (2006). International students' acculturation: Effects of international, conational, and local ties and need for closure. International Journal of Intercultural Relations, 30, 471-85.

Kim, Y. Y. (2001). Becoming intercultural: An integrative theory of communication and cross-cultural adaptation. Thousand Oaks, CA: Sage.

Kudo, K., \& Simkin, K.A. (2003). Intercultural Friendship Formation: the case of Japanese students at an Australian university. Journal of Intercultural Studies, 24(2), 91-114.

Mason, J. (2002). Qualitative researching (2nd ed.). London: Sage.

Maundeni, T. (2001). The role of social networks in the adjustment of African students to British society: Students' perceptions. Race, ethnicity and education, 4(3), 253-76. 
Merrick, B. (2004). Broadening our Horizons: international students in UK universities and colleges. UK Council for Overseas Student Affairs (UKCOSA). http://www.ukcisa.org.uk/files/pdf/about/reports/BOHreport.pdf Accessed 10 September 2013.

Montgomery, C., \& McDowell, L. (2009). Social networks and the international student experience: A community of practice? Journal of Studies in International Education, 13(4), 455-66.

Mount Royal University (MRU, 2012). Ethical considerations for dual-role research: Conducting research with students in your own classroom.

http://www.mtroyal.ca/cs/groups/public/documents/pdf/dualroleresearchers.pdf Accessed 21 January 2014.

Neri, F., \& Ville, S. (2008). Social capital renewal and the academic performance of international students in Australia. The Journal of Socio-Economics, 37, 1515-538.

Ong, A.S.J., \& Ward, C. (2005). The construction and validation of a social support measure for sojourners: The index of Sojourner Social Support (ISSS) Scale. Journal of CrossCultural Psychology, 36(6), 637-61.

Organisation for Economic Co-Operation and Development (OECD, 2012). Education at a glance 2012: OECD indicators. OECD Publishing. http://dx.doi.org/10.1787/eag-2012-en Accessed 20 September 2013.

Peacock, N. and Harrison, N. (2009). 'It's so much easier to go with what's easy': "Mindfulness" and the discourse between home and international students in the United Kingdom. Journal of Studies in International Education, 13(4), 487-508.

Ramsay, S., Jones, E., \& Barker, M. (2007). Relationship between adjustment and support types: Young and mature-aged local and international first year university students. Higher Education, 54(2), 247-65.

Rienties, B., Beausaert, S., Grohnert, T., Niemantsverdriet, S., \& Kommers, P. (2012). Understanding academic performance of international students: The role of ethnicity, academic and social integration. Higher Education, 63, 685-700.

Ryan, G.W., \& Bernard, H.R. (2003). Techniques to identify themes. Field Methods, 15(1), 85-109. 
Sakurai, T., McCall-Wolf, F., \& Kashima, E. S. (2010). Building intercultural links: The impact of a multicultural intervention programme on social ties of international students in Australia. International Journal of Intercultural Relations, 34, 176-85.

Sovic, Silvia (2009). Hi-bye friends and the herd instinct: International and home students in the creative arts. Higher Education, 58(6), 747-61.

UK Council for International Student Affairs (UKCISA, 2013). International student statistics. http://www.ukcisa.org.uk/content/2191/International-student-statistics Accessed 18 September 2013.

UNITE (2006). The international student experience report. Bristol, UNITE. http://www.unite-group.co.uk/binaries/MungoBlobs-1350377092270.pdf Accessed 18 September 2013.

Ward, C., Bochner, S., \& Furnham, A. (2001). The psychology of culture shock (2 ${ }^{\text {nd }}$ ed.). Hove: Routledge.

Wilcox, P., Winn, S., \& Fyvie-Gaud, M. (2005). 'It was nothing to do with the University, it was just the people': The role of social support in the first-year experience of higher education. Studies in Higher Education, 30(6), 707-22.

Williams, M. (2003). Making sense of social research. London: Sage.

Woolf, M. (2007). Impossible things before breakfast: Myths in education abroad. Journal of Studies in International Education, 11, 496-509.

Wright, C., \& Author (2013). 'I can't...I won't?' International students at the threshold of social interaction. Journal of Research in International Education, 12(2), 113-28.

Young, T.J., \& Author (2014). The effects of cross-cultural communication education on international students' adjustment and adaptation. Journal of Multilingual and Multicultural Development. doi: 10.1080/01434632.2014.884099

Young, T. J., Sercombe, P. G., Sachdev, I., Naeb, R., \& Author 2012. Success factors for international postgraduate students' adjustment: Exploring the roles of intercultural competence, language proficiency, social contact and social support. European Journal of Higher Education, 3, 151-71. 